\title{
A MATLAB/GUI BASED FAULT SIMULATION TOOL FOR POWER SYSTEM EDUCATION
}

\author{
Savaş Koç*, Zafer Aydoğmuş** \\ * Department of Electrical Education, \\ Batman University Technical Education Faculty- BATMAN \\ ** Department of Electrical Education, \\ Firat University Technical Education Faculty - ELAZIĞ
}

\begin{abstract}
A MATLAB/GUI (Graphical User Interface) based simulation tool has been developed to calculate the short-circuit fault currents in power transmission lines and to use as an educational material for courses on power system analysis. Presented program provides the calculation of three-phase (3LS), single line-to-ground (1LG), line-to-line (2LS), and double line-to-ground (2LG) faults on transmission lines. Symmetrical components of currents and voltages are used for calculations in the program. By means of the program, calculated fault currents and voltages on the fault point of the line have been presented both in per-unit and in real values. Furthermore, this calculated currents and voltages can be observed in GUI screen. In this way, an educational tool has been developed for the students to check the accuracy of their calculations and to observe the variations of waveforms. The purpose of this GUI based tool is to help the student to understand the concept of symmetrical components and short-circuit faults.
\end{abstract}

Keywords: Short circuit, Symmetrical components, Graphical User Interface.

\section{INTRODUCTION}

There are a number of different types of faults that may occur in power systems. Three phase symmetrical fault occurs in three phase systems where the phase conductors are in contact with each other. The phase to phase fault occurs when two phase conductors are in contact with each other. A single phase to ground fault occurs between a phase conductor and neutral conductor or ground conductor in three phase grounded neutral systems. If two phase conductors are in contact with the neutral or ground conductor, a two phase to ground fault occurs.

Fault analysis is very important part of power system analysis. Students have difficulties to understand the concept of faults and method of calculations. Teaching symmetrical fault analysis is easier than teaching unsymmetrical faults to the students. One reason for the difficulty can be attributed to the increased numerical complexity in dealing with the symmetrical components in the unbalanced three phase environment. This complexity leads to a loss of focus and lack of understanding of the basic processes affecting the values of currents and voltages after the occurrence of a fault and the students become indifferent to the variation in the results from one type of fault to another [1]. 
Using visual tools to calculate and present the variations, makes the concept of fault more understandable and lasting to the students. Graphical User Interfaces (GUI) is one of the visual tools to provide the user with interactive visual communication with the tasks on hand and the solution process. With GUI, the student can start applying the application software to solve the problem more efficiently. The GUI environment keeps most of the tedious and repetitive calculations in the background, allowing the user to spend more time in the analysis of the results obtained. Many power system analysis applications have been developed taking advantage of GUI [2].

In this study, a MATLAB/GUI (Graphical User Interface) based simulation tool has been developed to calculate the short-circuit fault currents in power transmission lines. This simulation tool can be used as an educational material for course of power system analysis. The program provides the calculation of four different faults on transmission lines. For calculations of fault currents and voltages symmetrical components are used. A GUI-based user-friendly interface has been developed. The students are also able to see the graphical variations of fault currents and voltages in GUI screen.

\section{SYMMETRICAL COMPONENTS}

The method of symmetrical components allows to solve unbalanced systems using balanced techniques. This method was introduced by C.L. Fortescue in 1918. The theory of Fortescue was proposed in which, an unbalanced system of "n" related phasors can be resolved into " $n$ " systems of balanced phasors called Symmetrical Components of the original phasors. The " $n$ " phasors of each set of components are equal in length, and the angles between adjacent phasors of the set are equal. Applying Fortescue's theorem to three unbalanced phasors of a three phase system, the following balanced sets of components can be obtained [2]:

1. Three Positive sequence components, equal in magnitude, displaced from each other by 120 degrees as shown in Figure 1, with the same phase sequence as the original phasors .

2. Three Negative sequence components, equal in magnitude, displaced from each other by 120 degrees as shown in Figure 1, with a phase sequence opposite to that of the original phasors.

3. Three Zero sequence components, equal in magnitude, as shown in Figure 1, with zero phase displacement from each other.

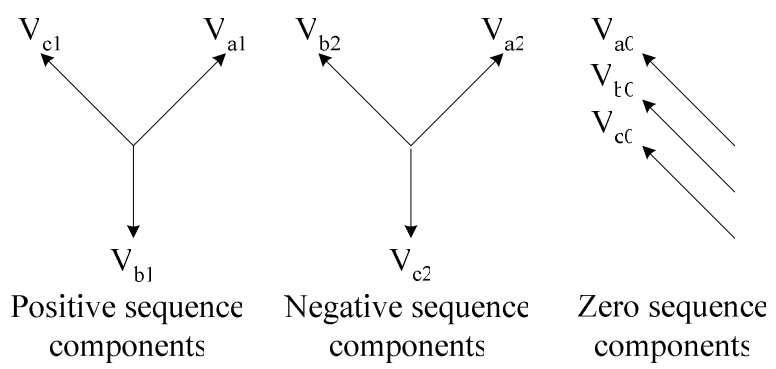

Figure 1. Three balanced sets of symmetrical components of three unbalanced voltage phasors. 
Original phase voltages are shown as $\mathrm{V}_{\mathrm{a}}, \mathrm{V}_{\mathrm{b}}$ and $\mathrm{V}_{\mathrm{c}}$. The subscripts $\mathrm{a}, \mathrm{b}$ and $\mathrm{c}$ refer to the three phase voltages and the subscripts 1,2 and 0 refer to positive, negative and zero sequence components, respectively. Each of the original unbalanced phasors is the sum of its symmetrical components [3].

$\mathrm{V}_{\mathrm{a}}=\mathrm{V}_{\mathrm{a} 0}+\mathrm{V}_{\mathrm{a} 1}+\mathrm{V}_{\mathrm{a} 2}$
$\mathrm{~V}_{\mathrm{b}}=\mathrm{V}_{\mathrm{b} 0}+\mathrm{V}_{\mathrm{b} 1}+\mathrm{V}_{\mathrm{b} 2}$
$\mathrm{~V}_{\mathrm{c}}=\mathrm{V}_{\mathrm{c} 0}+\mathrm{V}_{\mathrm{c} 1}+\mathrm{V}_{\mathrm{c} 2}$

In a power system, symmetrical components are displaced from each other by 120 degrees. An a operator is developed to indicate the phase difference between these phasors. a operator is represented by complex numbers [4].

$\mathrm{a}=1 \angle 120^{0}=1 . \mathrm{e}^{\mathrm{j} 2 \pi / 3}=-0.5+\mathrm{j} 0.866$

Using operator a, three phase components have been expressed by single phase component. $\mathrm{V}_{\mathrm{b}}$ and $\mathrm{V}_{\mathrm{c}}$ components can be defined with $\mathrm{V}_{\mathrm{a}}$ component and operator $\mathrm{a}$ $[3]$.

$\begin{aligned} \mathrm{V}_{\mathrm{b} 1} & =\mathrm{a}^{2} \mathrm{~V}_{\mathrm{a} 1} \\ \mathrm{~V}_{\mathrm{c} 1} & =\mathrm{aV}_{\mathrm{a} 1} \\ \mathrm{~V}_{\mathrm{b} 2} & =\mathrm{aV}_{\mathrm{a} 2} \\ \mathrm{~V}_{\mathrm{c} 2} & =\mathrm{a}^{2} \mathrm{~V}_{\mathrm{a} 2} \\ \mathrm{~V}_{\mathrm{b} 0} & =\mathrm{V}_{\mathrm{a} 0} \\ \mathrm{~V}_{\mathrm{c} 0} & =\mathrm{V}_{\mathrm{a} 0}\end{aligned}$

Substituting equations (5-10) into equations (1-3) respectively, we can get the phase voltages.

$$
\begin{aligned}
& \mathrm{V}_{\mathrm{a}}=\mathrm{V}_{\mathrm{a} 0}+\mathrm{V}_{\mathrm{a} 1}+\mathrm{V}_{\mathrm{a} 2} \\
& \mathrm{~V}_{\mathrm{b}}=\mathrm{V}_{\mathrm{a} 0}+\mathrm{a}^{2} \mathrm{~V}_{\mathrm{a} 1}+\mathrm{aV}_{\mathrm{a} 2} \\
& \mathrm{~V}_{\mathrm{c}}=\mathrm{V}_{\mathrm{a} 0}+\mathrm{aV}_{\mathrm{a} 1}+\mathrm{a}^{2} \mathrm{~V}_{\mathrm{a} 2}
\end{aligned}
$$

The symmetrical components of phase voltages could be written as a matrix equation.

$$
\left|\begin{array}{c}
\mathrm{V}_{\mathrm{a}} \\
\mathrm{V}_{\mathrm{b}} \\
\mathrm{V}_{\mathrm{c}}
\end{array}\right|=\left|\begin{array}{ccc}
1 & 1 & 1 \\
1 & \mathrm{a}^{2} & \mathrm{a} \\
1 & \mathrm{a} & \mathrm{a}^{2}
\end{array}\right| \cdot\left|\begin{array}{c}
\mathrm{V}_{\mathrm{a} 0} \\
\mathrm{~V}_{\mathrm{a} 1} \\
\mathrm{~V}_{\mathrm{a} 2}
\end{array}\right|
$$

where; A matrix is expressed

$$
\mathrm{A}=\left|\begin{array}{ccc}
1 & 1 & 1 \\
1 & \mathrm{a}^{2} & \mathrm{a} \\
1 & \mathrm{a} & \mathrm{a}^{2}
\end{array}\right|
$$


then $\mathrm{A}^{-1}$ may be expressed as;

$\mathrm{A}^{-1}=\frac{1}{3}\left|\begin{array}{ccc}1 & 1 & 1 \\ 1 & \mathrm{a} & \mathrm{a}^{2} \\ 1 & \mathrm{a}^{2} & \mathrm{a}\end{array}\right|$

Multiplying by $\mathrm{A}^{-1}$ to both side of the equation (14), we can get the following matrix:

$\left|\begin{array}{c}\mathrm{V}_{\mathrm{a} 0} \\ \mathrm{~V}_{\mathrm{a} 1} \\ \mathrm{~V}_{\mathrm{a} 2}\end{array}\right|=\frac{1}{3}\left|\begin{array}{ccc}1 & 1 & 1 \\ 1 & \mathrm{a} & \mathrm{a}^{2} \\ 1 & \mathrm{a}^{2} & \mathrm{a}\end{array}\right| \cdot\left|\begin{array}{c}\mathrm{V}_{\mathrm{a}} \\ \mathrm{V}_{\mathrm{b}} \\ \mathrm{V}_{\mathrm{c}}\end{array}\right|$

The current equations could be written similar to the voltage equations.

$\mathrm{I}_{\mathrm{a}}=\mathrm{I}_{\mathrm{a} 0}+\mathrm{I}_{\mathrm{a} 1}+\mathrm{I}_{\mathrm{a} 2}$
$\mathrm{I}_{\mathrm{b}}=\mathrm{I}_{\mathrm{a} 0}+\mathrm{a}^{2} \mathrm{I}_{\mathrm{a} 1}+\mathrm{aI}_{\mathrm{a} 2}$
$\mathrm{I}_{\mathrm{c}}=\mathrm{I}_{\mathrm{a} 0}+\mathrm{aI}_{\mathrm{a} 1}+\mathrm{a}^{2} \mathrm{I}_{\mathrm{a} 2}$

where $I_{a}, I_{b}$ and $I_{c}$ are phase currents and $\mathrm{Ia}_{0}, \mathrm{Ia}_{1}$ and $\mathrm{Ia}_{2}$ are zero, positive and negative sequence components of currents respectively. Thevenin equivalent circuits as seen from the fault point are shown in Figure 2. And in matrix form it can be written as follow;

$\left|\begin{array}{c}I_{a} \\ I_{b} \\ I_{c}\end{array}\right|=\left|\begin{array}{ccc}1 & 1 & 1 \\ 1 & a^{2} & a \\ 1 & a & a^{2}\end{array}\right| \cdot\left|\begin{array}{c}I_{a} \\ I_{a 1} \\ I_{a 2}\end{array}\right|$

and symmetrical components can be given

$$
\left|\begin{array}{c}
\mathrm{I}_{\mathrm{a} 0} \\
\mathrm{I}_{\mathrm{a} 1} \\
\mathrm{I}_{\mathrm{a} 2}
\end{array}\right|=\frac{1}{3}\left|\begin{array}{ccc}
1 & 1 & 1 \\
1 & \mathrm{a} & \mathrm{a}^{2} \\
1 & \mathrm{a}^{2} & \mathrm{a}
\end{array}\right| \cdot\left|\begin{array}{c}
\mathrm{I}_{\mathrm{a}} \\
\mathrm{I}_{\mathrm{b}} \\
\mathrm{I}_{\mathrm{c}}
\end{array}\right|
$$

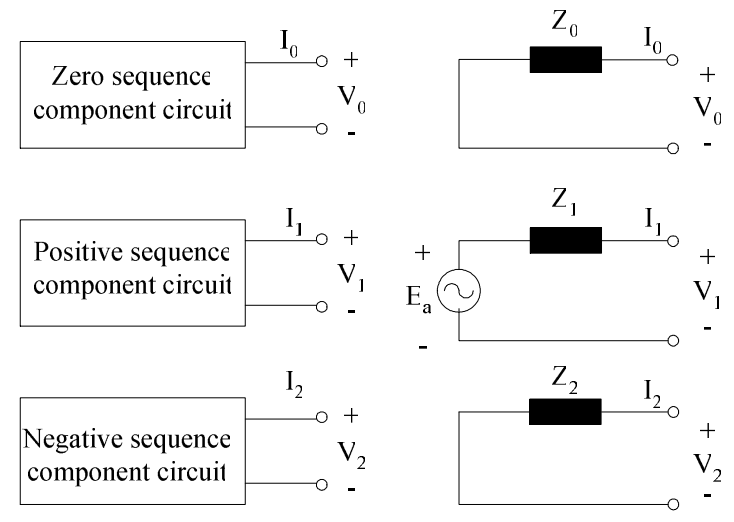

(b)

Figure 2. Symmetrical component circuits in three phase balanced system.

a) Symmetrical component circuits,

b) Thevenin equivalent circuits as seen from the fault point. 


\section{FAULT CALCULATION IN THREE PHASE SYSTEMS}

To calculate the symmetrical and unsymmetrical faults, firstly, the positive sequence component of phase-a has been calculated. Thus, sequence reactances of thevenin equivalent circuits $\left(Z_{1}, Z_{2}, Z_{0}\right)$ have been calculated. The fault currents of sequences have been determined by using these reactances and phase voltage $E_{a}$. The current and voltage values of other phases could be calculated via these components.

\subsection{Three-phase fault}

$$
\begin{aligned}
I_{a 1} & =\frac{E_{a}}{Z_{1}} \\
I_{a 0} & =0 \\
I_{a}=0 &
\end{aligned}
$$

where $E_{a}$ and $Z_{1}$ are phase voltage and positive sequence reactance.

\subsection{Single-phase to ground fault}

$$
\begin{aligned}
& I_{\mathrm{a} 1}=\frac{E_{a}}{Z_{0}+Z_{1}+Z_{2}} \\
& I_{a 0}=I_{a 2}=I_{a 1}
\end{aligned}
$$

where $Z_{0}$ and $Z_{2}$ are zero and negative sequence reactances.

\subsection{Phase-phase fault}

$$
\begin{aligned}
& \mathrm{I}_{\mathrm{a} 1}=\frac{\mathrm{E}_{\mathrm{a}}}{Z_{1}+\mathrm{Z}_{2}} \\
& \mathrm{I}_{\mathrm{a} 2}=-\mathrm{I}_{\mathrm{a} 1} \\
& \mathrm{I}_{\mathrm{a} 0}=0
\end{aligned}
$$

\subsection{Two-phase to ground fault}

$$
\begin{aligned}
& I_{a 1}=\frac{E_{a}}{Z_{1}+\frac{Z_{0} \cdot Z_{2}}{Z_{0}+Z_{2}}} \\
& I_{a 0}=-\frac{Z_{2}}{Z_{0}+Z_{2}} I_{a 1} \\
& I_{a 2}=-\frac{Z_{0}}{Z_{0}+Z_{2}} I_{a 1}
\end{aligned}
$$

The currents have been calculated by using positive, negative and zero components of phase-a for each fault (Eq. 21). Additionally, the symmetrical components of voltage of phase-a has calculated by using Equation (34). Other phase voltages have been 
determined via the voltage of phase-a. The positive sequence reactance must be calculated from Equation.(35) for the time variations of signals.

$$
\begin{aligned}
& \left|\begin{array}{c}
\mathrm{V}_{\mathrm{a} 0} \\
\mathrm{~V}_{\mathrm{a} 1} \\
\mathrm{~V}_{\mathrm{a} 2}
\end{array}\right|=\left|\begin{array}{c}
0 \\
\mathrm{E}_{\mathrm{a}} \\
0
\end{array}\right|-\left|\begin{array}{ccc}
\mathrm{Z}_{0} & 0 & 0 \\
0 & \mathrm{Z}_{1} & 0 \\
0 & 0 & \mathrm{Z}_{2}
\end{array}\right| \cdot\left|\begin{array}{c}
\mathrm{I}_{\mathrm{a} 0} \\
\mathrm{I}_{\mathrm{a} 1} \\
\mathrm{I}_{\mathrm{a} 2}
\end{array}\right| \\
& X_{1}(t)=\left\{\left(\frac{1}{X_{d}^{\prime \prime}}-\frac{1}{X_{d}^{\prime}}\right) e^{-t / T_{d}^{\prime \prime}}+\left(\frac{1}{X_{d}^{\prime}}-\frac{1}{X_{d}}\right) e^{-t / T_{d}^{\prime}}+\frac{1}{X_{d}}\right\}^{-1}
\end{aligned}
$$

Where; $X_{d}{ }^{\prime}, X_{d}, X_{d}$ : direct-axis subtransient, transient and synchronous reactances, $\mathrm{T}_{\mathrm{d}}{ }^{\prime \prime}, \mathrm{T}_{\mathrm{d}}$ ' : direct-axis fault subtransient and transient time constants,

$E_{a}, E$ : complex and RMS value of phase-a voltage of synchronous machine terminal before the fault occurrence.

The Table. 1 could be used for calculating and drawing the fault current and voltages. The signals must be drawn by taking into account the real parts of current equations. After finding the symmetrical components of a phase current, the value of current and voltage can be calculated. Thevenin equivalent circuits are shown considering the fault conditions [5].

Table.1 Symmetrical -components circuit constants and fault currents

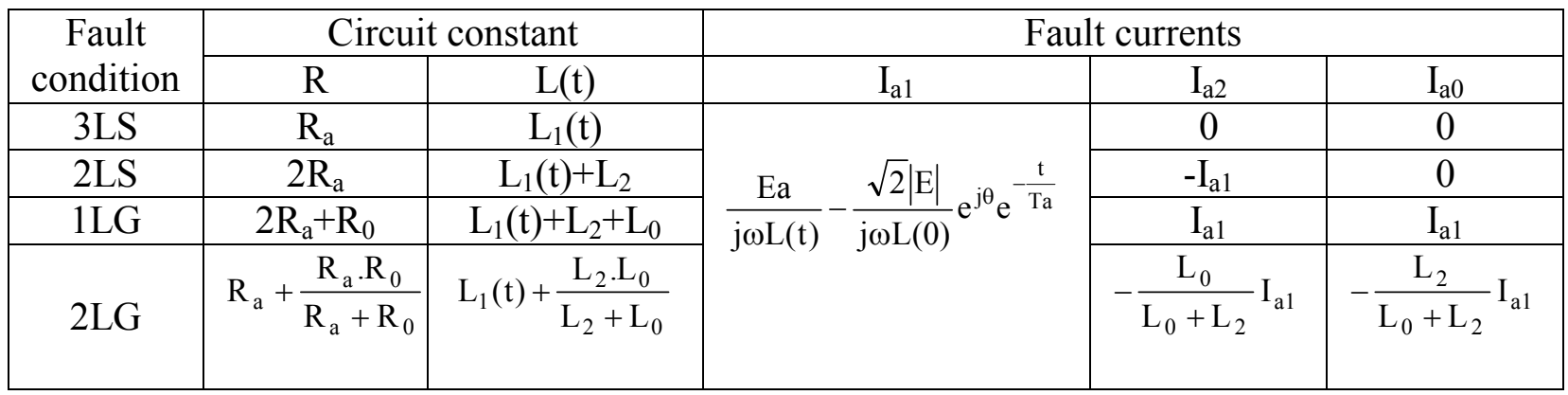

Note; $\mathrm{T}_{\mathrm{a}}=\frac{\mathrm{L}(0)}{\mathrm{R}}, \mathrm{X}_{2}=\omega \mathrm{L}_{2}, \mathrm{X}_{0}=\omega \mathrm{L}_{0}, \mathrm{E}_{\mathrm{a}}=\sqrt{2}|\mathrm{E}| \mathrm{e}^{\mathrm{j}(\omega t+\theta)}$

Where; $T_{a}$ is armature time constant, $L(0)$ is initial inductance at $t=0, R_{a}$ and $R_{0}$ are armature resistance and zero-phase-sequence resistances, $\mathrm{L}_{1}(\mathrm{t}), \mathrm{L}_{2}$ and $\mathrm{L}_{0}$ are positive, negative and zero-phase-sequence inductances, respectively. 


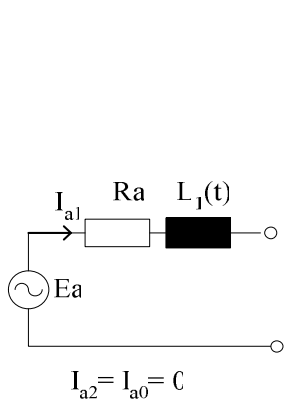

(a) $3 \mathrm{LS}$

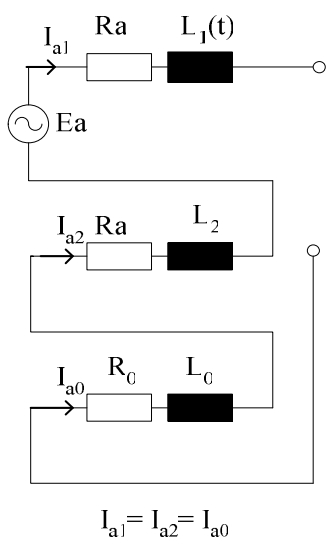

(c) $1 \mathrm{LG}($ Faz-a)

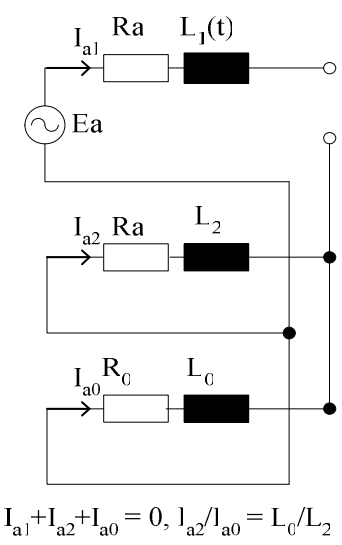

(d) $2 \mathrm{LG}(\mathrm{Faz}-\mathrm{b} / \mathrm{c})$

Figure3. Equivalent circuits for common fault conditions.

\section{STRUCTURE OF DEVELOPED INTERFACE}

A MATLAB/GUI based simulation tool for fault calculations has been developed. The flowchart of the developed interface has been shown in Figure 4.

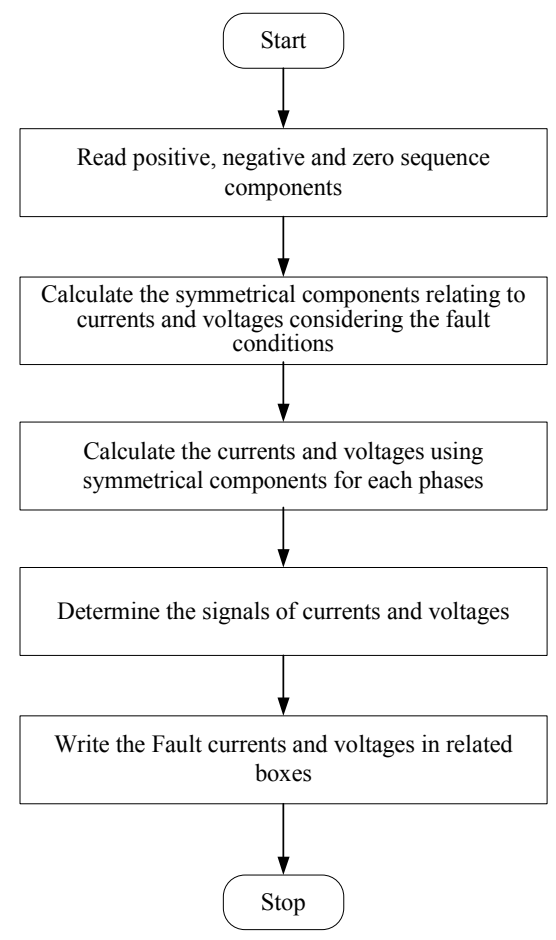

Figure 4. Flowchart of the developed interface.

In the beginning of the programming process, input boxes has been generated for entering the reactances of symmetrical components, base power and voltage of the power system. These boxes have been shown in Figure 5a. 


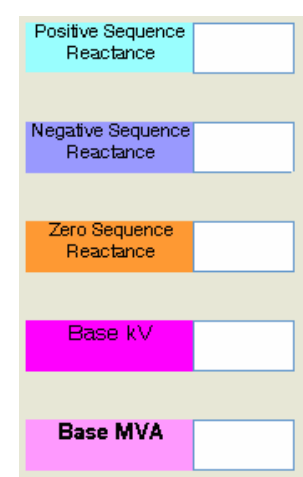

(a)

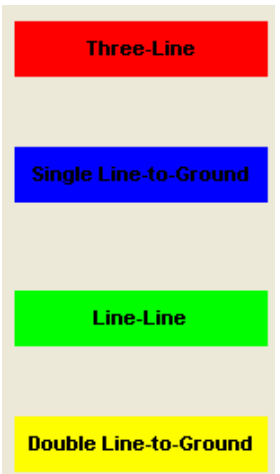

(b)

Figure 5. Input boxes for a) Sequence reactances, base power and voltage of the system, b) Fault conditions.

The program senses all the input values as character string. After the entering of input values, the values have been converted to numeric values and the fault calculations have been performed according to the chosen fault condition. The fault boxes have been shown in Figure 5b. After the calculation, the achieved values have been converted to the character string and displayed in boxes. The results have been shown both in real and per-unit. And interface offers time varying signals of fault currents and voltages (in Figure 6).

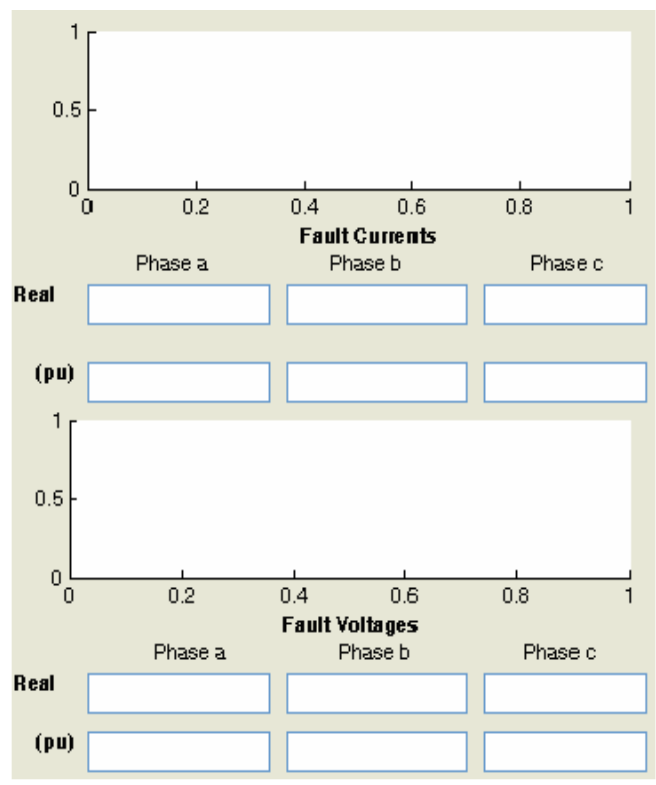

Figure 6. Time varying signals of fault currents and voltages.

\section{SAMPLE APPLICATION}

A sample system has been implemented to show the validity of the program. The values of Thevenin equivalent reactances of the system, base power and base voltage are shown in Table 2. The program has been operated by using these values to achieve the results of fault currents and voltages. The developed program is named "education". 
Table 2. The values of the system parameters used in program.

\begin{tabular}{|l|c|c|}
\hline \multicolumn{1}{|c|}{ Name of variable } & Symbol & Value \\
\hline Positive sequence reactance $(\mathrm{pu})$ & $\mathrm{Z}_{1}$ & 0.603 \\
\hline Negative sequence reactance $(\mathrm{pu})$ & $\mathrm{Z}_{2}$ & 0.603 \\
\hline Zero sequence reactance $(\mathrm{pu})$ & $\mathrm{Z}_{0}$ & 0.089 \\
\hline Base voltage $(\mathrm{kV})$ & $\mathrm{kVB}$ & 11 \\
\hline Base power $(\mathrm{MVA})$ & $\mathrm{MVAB}$ & 50 \\
\hline
\end{tabular}

The results of fault calculations and graphical presentation of Three-Phase Fault has been shown in Figure 7.

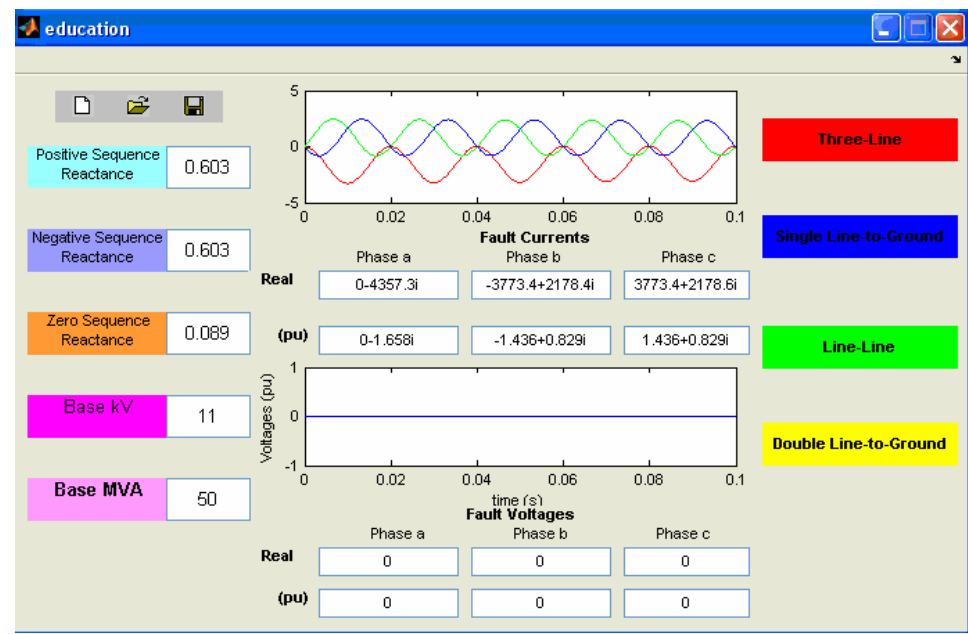

Figure 7. Fault calculations and graphical presentation of Three-Phase Fault.

In Figure 8, the results about Single-Phase to Ground Fault has been given.

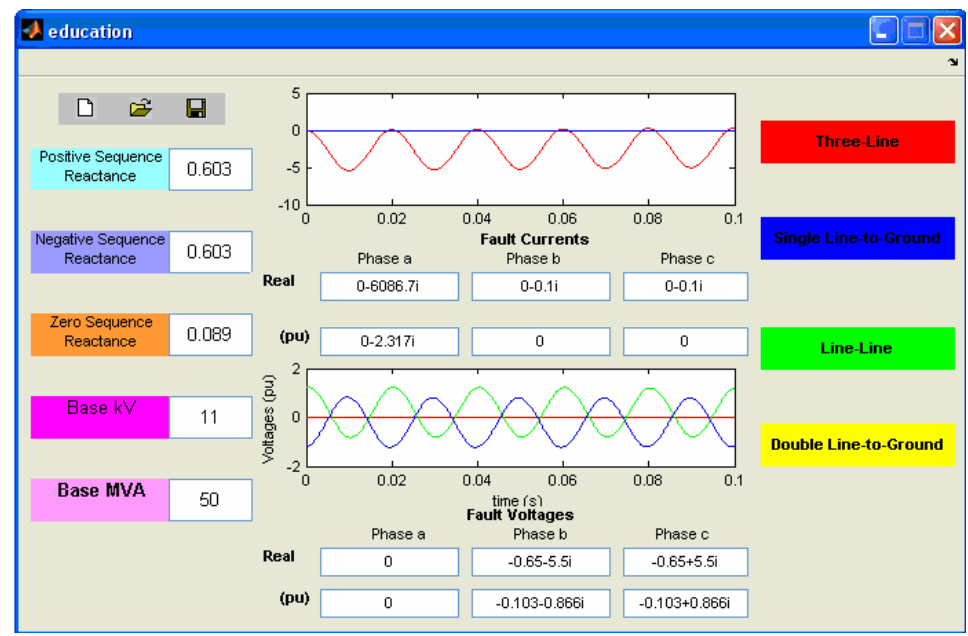

Figure 8 Fault calculations and graphical presentation of Single-Phase to Ground Fault. 
Figure 9 shows the results of Phase-Phase Fault of the system.

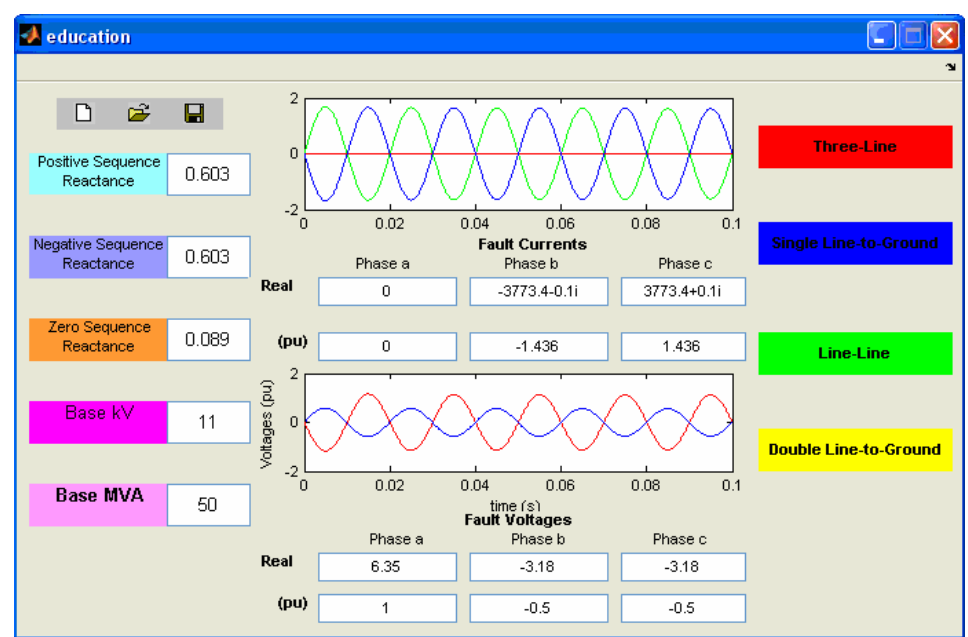

Figure 9. The calculations and graphical representations of Phase-Phase Fault.

The results of fault calculations and graphical presentation of Two-Phase to Ground Fault has been given in Figure 10.

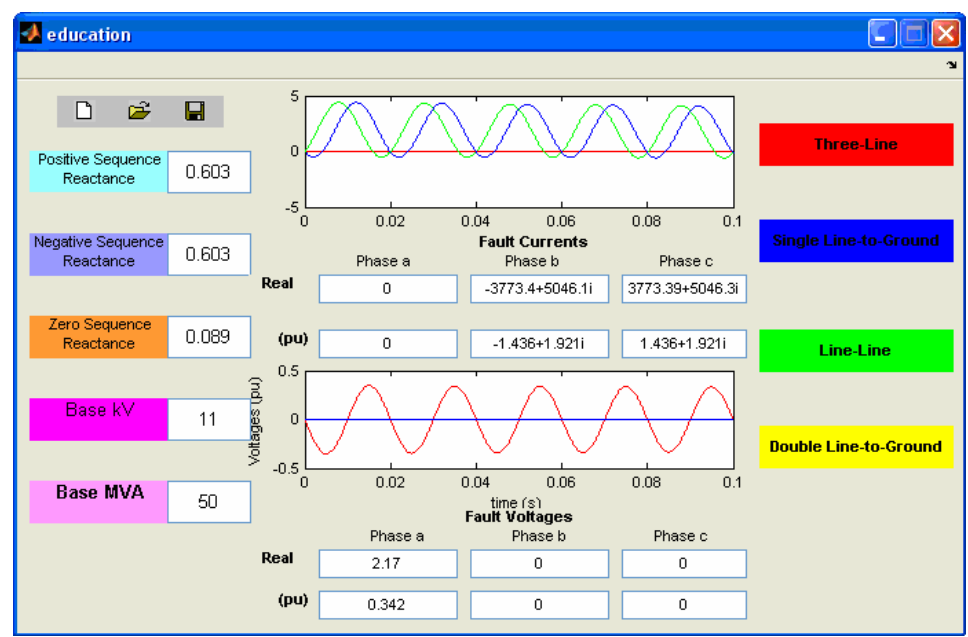

Figure 10. Two-Phase to Ground Fault results of the system using the program named education.

The program allows to the user to create new session by using first $\square$ button on left upper side of the screen. And it is possible to load a previously saved file by pressing the 10 button. And the student can save the present data as a file by using button. 


\section{CONCLUSION}

A MATLAB/GUI based education tool has been developed to calculate the short-circuit faults in transmission systems by using symmetrical components method. This software provides a user-friendly interface to help the student to understand the symmetrical components and fault calculations. After the entering of the system parameters, the student chooses one of the four fault options. By choosing the fault type, all the calculations of fault currents and voltages have been performed. In this interface, the graphical representation of current and voltages is available. A simple and easy-touse interface allows the student to check his/her answers that he/her was doing the calculations by hand. This interface can be used as an educational tool for power systems.

\section{REFERENCES}

[1] R. F. Ghajar, and K. Saikali, A User-Friendly and Fast Program for the Simulation of Power System Faults, The 7th IEEE International Conference on Electronics, Circuits and Systems, 2, 729-732, 2000.

[2] D. C. Yu, D. Chen, S. Ramasamy and D. G. Flinn, A Windows Based Graphical Package for Symmetrical Components Analysis, IEEE Transactions on Power Systems, 10(4), 1742-1749, 1995.

[3] C. L. Fortescue, Method of Symmetrical Coordinates Applied to the Solution of Polyphase Networks, Trans. AIEE, pt. II, 37, 1027-1140, 1918.

[4] M.E. El- Hawary, Electrical Power Systems, IEEE Press, Power Systems Engineering Series, 2002.

[5] T. Kai, N. Takeuchi, T. Funabashi, H. Sasaki, A Simplified Fault Currents Analysis Method considering Transient of Synchronous Machine, IEEE Transactions on Energy Conversion, 12(3), 225-231, 1997. 